\title{
Prevention of Railway Accident using Arduino Based Safety System: A case Study of Addis Ababa Light Rail Transit
}

\author{
Adoh Lucky Ugochukwu ${ }^{1 *}$, Akello Fiona Mercy ${ }^{2}$, Nyangassa Faraja ${ }^{2}$, Ishimwe Pascasie ${ }^{2}$ \\ 1*African Railway Centre of Excellence, Addis Ababa University, Ethiopia. \\ Federal University of Technology, Akure, Nigeria. \\ ${ }^{2}$ African Railway Centre of Excellence, Addis Ababa University, Ethiopia.
}

\begin{abstract}
Obstacles on the right of way of the train, smoke on the train and flooding on the track can cause derailment, collision, injuries to train passengers, environmental damage and loss of properties, so there is a need to look at various ways to prevent or reduce the frequency and severity of these accidents by using Arduino based safety system to mitigate this accidents. The aim of this paper is to simulate a program in Proteus to detect obstacles on the right of way of trains, flood on the railway track and smoke in the train. Arduino code is written to detect obstacle on the track as well as fire in the trains, and floods in the railway track and simulated in Proteus. The result shows that this new innovative technology will increase the reliability of safety systems of railway. By implementing these features in real time application, we can avoid accidents up to a very significant margin.
\end{abstract}

Keywords - Accident, Arduino, Proteus, track

\section{INTRODUCTION}

Transport plays a vital role because it enables the act of buying and selling goods and services between persons which is a pre-requisite for the development of a Nation. Transportation has throughout history been a spur to expansion as better transport leads to more trade. The stage in an economic cycle has always been dependent on increasing the capacity and rationality of transport. But the infrastructure and operation of transport has a great effect on the land and is the largest drainer of energy, making transport sustainability and safety a major issue.

Derailment occurs when a vehicle such as a train runs off its rails. Usually, the derailment of a train can be caused by a collision with another object, an operational error, the mechanical failure of the tracks, such as broken rails, or mechanical failure of the wheels. In Ethiopia, the Ethiopian Railway Corporation has in the recent past experienced monetary loss due to train derailment on the DjiboutiEthiopia line caused by collision with animals and block materials in the country side areas of Ethio-Djibouti line. Obstacles on the right of way of the train (track), smoke on the train and flooding on the track can cause derailment, collision, injuries to train passengers, environmental damage and loss of properties. So there is a need to look at various ways to prevent or reduce the frequency and severity of the these accidents by using Arduino based safety system to mitigate this accidents.

In this paper, ultrasonic, rain and smoke sensors will be used for obstacle detection of object on the track, flood on the track and fire in the train and the detection is done as trains move along the railway track. The aim of this paper is to simulate a program in Proteus to detect obstacles on the right of way of the train, flood on the railway track and smoke on the train.

The sensors used for this simulation is explained below;

\subsection{Smoke Sensor}

A smoke detector is a sensor that detects smoke as a primary indication of fire. It functions is simply with a detection element inside the device that activates when it reaches a fixed temperature or an extreme increase in temperature occurs [1].

\section{Accident caused by fire in Trains}

Fire incidences in trains are among the most serious disasters to human lives and the property of railways. Thus the prevention of train fire has become a serious concern for Railways. A train fire is different from a fire in other places in the manner in which it breaks out, grows and spreads, and in the method of fighting it, as well as the damages it causes. Fire especially in uncontrolled state is a source of very rapid destruction and this gets compounded when loss of human life is involved. Hence, taking all possible steps to prevent train fire from breaking out in coaches, and if it breaks out, to prevent it from spreading and causing further damage is being given great importance. In order to prevent such accident caused by fire in train we can use fire/smoke sensor in order to detect fire [1].

\subsection{Ultrasonic sensors}

An ultrasonic transducer is a proximity sensor that converts energy into ultrasonic sound, or sound waves above the normal range of human hearing. With $2.5-5.5 \mathrm{~V}$ power the LV-Max Sonar provides very short to long-range detection and ranging, in an incredibly small package. The LVMaxSonar EZ detects objects from 0-inches to 254inches. (6.45-meters) and provides sonar range information from 6 -inches out to 254 - inches with 1 -inch resolution. Objects from 0 -inches to 6-inches range as 6-inches.

Modern level crossings (or railroad crossings) have come a long way from the early days of human railway employees waving red flags and shining lanterns to clear railroad tracks of vehicles and pedestrian traffic for reaching trains. As still the case today, nineteenth century railways were deeply concerned with preventing accidents and protecting resources. Respond to this concern, railroad began to 
implement manual, and eventually electrical, boom gates (crossing barriers) to block road traffic from the rail tracks. Although plain, easy signage may be plenty for level crossings in sparsely inhabit region, high traffic intersection today often aspect active notice system, which include electrical explosion gates, blinking lights, and caution bells that are triggered when an approaching train trips a nearby track circuit [2]. All ultrasonic sensors are used to detect arrival and departure of the gate near and away to the railway crossing respectively. They are placed at two sides of railway crossings. Ultrasonic sensor gives the accurate distance in terms of centimeter so that we can detect the train. Train is passing the railway crossing. The detection of two ultrasonic sensors is placed to detect arrival of the train and departure of train is done by using two ultrasonic train and both also detect departure of the gate. Ultrasonic sensors used at two ends for checking of train arrival and departure. The distance at which the ultrasonic sensor is placed is properly selected so that the gates close in times. As the train approaches the ultrasonic sensor, it detects the train and the servo which is a replica of automatic gates in our project will close or open according to the condition. At one end, if obstacles are detected, condition for presence of train will be ON, gates will be closed, Receiving again the original condition, gates will be OPEN. Same case will be observed for train travelling otherwise [3]. The logically coupled ultrasonic sensors sense the direction in which train is moving and correspondingly display measures on LCD screen. The ultrasonic sensors then logically control the opening/closing operation of gates (servo motors) [4]. For this paper, the ultrasonic sensor shall be used as a proximity sensor used to sense object on the track. When the distance between the train and object is less than $5 \mathrm{~cm}$, it sends an alarm to the driver to stop the train.

\subsection{3. Rain sensor}

Flooding is another problem often required to control the overflow of water that submerges the land on which train runs. The track goes underwater and consequently it becomes unable to carry train and the result is derailment. So, if we use a flood sensor then this type of accidents maybe detected before it happens. The Flood sensor module is an easy tool for flood detection. It can be used as a switch when water drop falls through the board and also for measuring falling intensity. The flood sensor placed near railway track at appropriate places send the signal whenever the overflow occurs [5]. A water detector is an electronic device that is designed to detect the presence of water for purposes such as to provide an alert in time to allow the prevention of water leakage. A common design is a small cable or device that lies flat on a floor and relies on the electrical conductivity of water to decrease the resistance across two contacts. The device then sounds an audible alarm together with providing onward signaling in the presence of enough water to bridge the contacts. Rain sensor is designed for water detection, which can be widely used in sensing rainfall, water level, and even liquid leakage. Connecting a water sensor to an Arduino is a great way to detect a leak, spill, flood, rain, etc on the railway track and on the train.

\subsection{METHODOLOGY}

\subsection{Main component specifications in the connection} Arduino UNO Microcontroller

The Arduino Uno R3 is a microcontroller board based on a removable, dual-inline-package (DIP) ATmega328 AVR microcontroller. It has 20 digital input/output pins (of which 6 can be used as PWM outputs and 6 can be used as analog inputs). Programs can be loaded on to it from the easy-touse Arduino computer program. The Arduino has an extensive support community, which makes it a very easy way to get started working with embedded electronics. The $\mathrm{R} 3$ is the third, and latest, revision of the Arduino Uno [6] as shown in Figure 1 below.

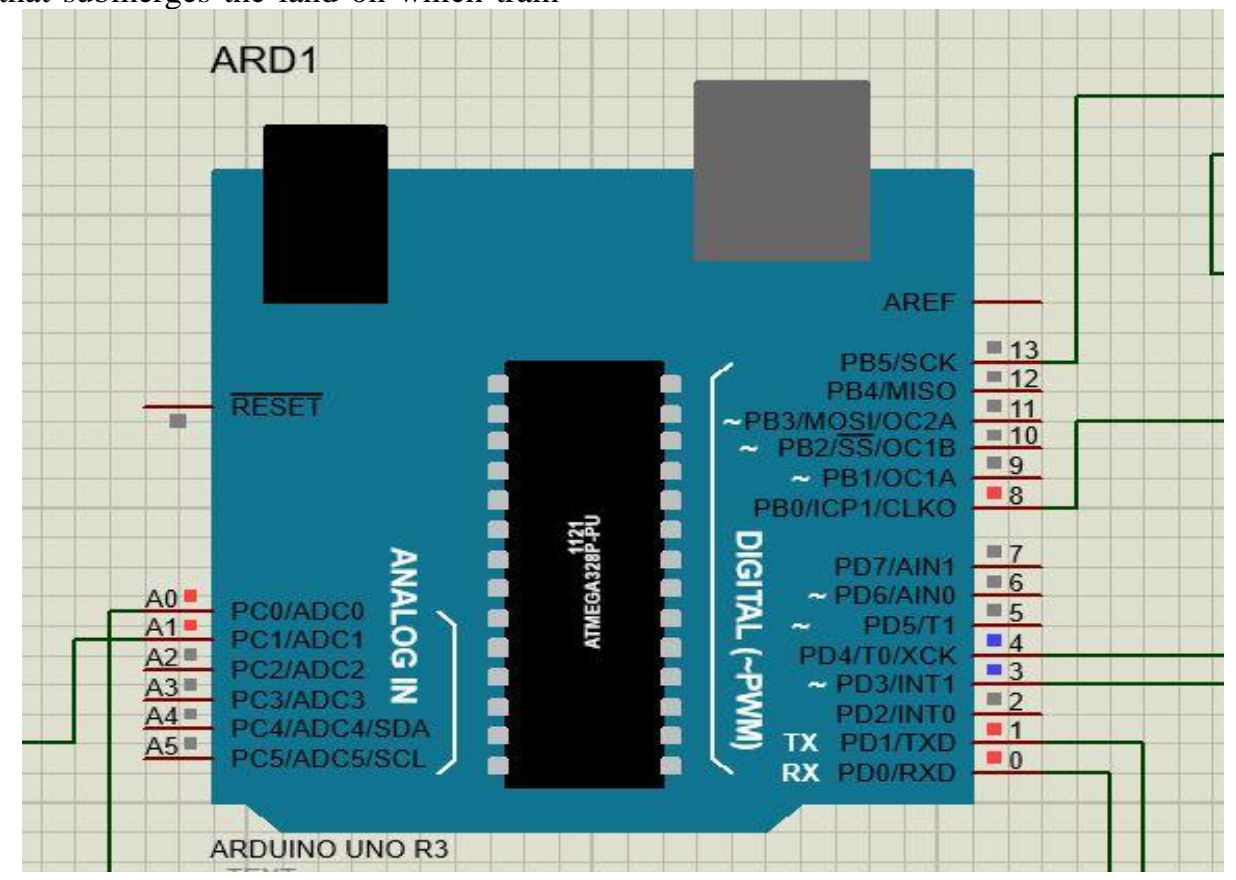

Figure 1. Arduino UNO R3 board 
Arduino board Specifications

Microcontroller : ATmega328

Operating Voltage: $5 \mathrm{~V}$

Input Voltage (recommended): $5 \mathrm{~V}$

Digital I/O Pins $14:$ PWMo/p

Analog Input Pins : 6 DC

Current per I/O Pin : $40 \mathrm{~mA}$

DC Current for 3.3V Pin : $50 \mathrm{~mA}$

\section{Ultrasonic Sensor module}

An Ultrasonic sensor is a device that can measure the distance to an object by using sound waves. It measures distance by sending out a sound wave at a specific frequency and listening for that sound wave to bounce back. By recording the elapsed time between the sound wave being generated and the sound wave bouncing back, it is possible to calculate the distance between the sonar sensor and the object [7]. The Ultrasonic sensor module is a convenient way for measuring distances from objects. This module has a lot of applications such as parking sensors, obstacle and terrain monitoring systems, industrial distance measurements, etc. It has a stable performance and high accuracy ranging from $2 \mathrm{~cm}$ to $450 \mathrm{~cm}$ with a resolution of $0.3 \mathrm{~cm}$. The module sends an ultrasonic signal, eight pulses of $40 \mathrm{kHz}$ square wave from the transmitter; the echo is then picked up by the receiver and outputs a waveform with a time period proportional to the distance. The connected microcontroller accepts the signal and performs necessary processing. The HC-SR04 Ultrasonic Distance Sensor is a sensor used for detecting the distance to an object using sonar. It's ideal for any robotics projects your have which require you to avoid objects, by detecting how close they are you can steer away from them. The HC-SR04 uses noncontact ultrasound sonar to measure the distance to an object, and consists of two ultrasonic transmitters (basically speakers), a receiver, and a control circuit. The transmitters emit a high frequency ultrasonic sound, which bounce off any nearby solid objects, and the receiver listens for any return echo. That echo is then processed by the control circuit to calculate the time difference between the signal being transmitted and received. This time can subsequently be used, along with some clever math, to calculate the distance between the sensor and the reflecting object [8].

The HC-SR04 Ultrasonic Sensor specification

- Input Voltage: $5 \mathrm{~V}$

- Current Draw: 20mA (Max)

- Digital Output: 5V

- Digital Output: 0V (Low)

- Working Temperature: $-15^{\circ} \mathrm{C}$ to $70^{\circ} \mathrm{C}$

- Sensing Angle: $30^{\circ}$ Cone

- Angle of Effect: $15^{\circ}$ Cone

- Ultrasonic Frequency: $40 \mathrm{kHz}$

- Range: $2 \mathrm{~cm}-400 \mathrm{~cm}$

- Dimensions

$\checkmark$ Length: $43 \mathrm{~mm}$

$\checkmark$ Width: $20 \mathrm{~mm}$

$\checkmark$ Height (with transmitters): $15 \mathrm{~mm}$

$\checkmark$ Centre screw hole distance: $40 \mathrm{~mm} \times 15 \mathrm{~mm}$

$\checkmark$ Screw hole diameter: $1 \mathrm{~mm}$ (M1)

$\checkmark$ Transmitter diameter: $8 \mathrm{~mm}$

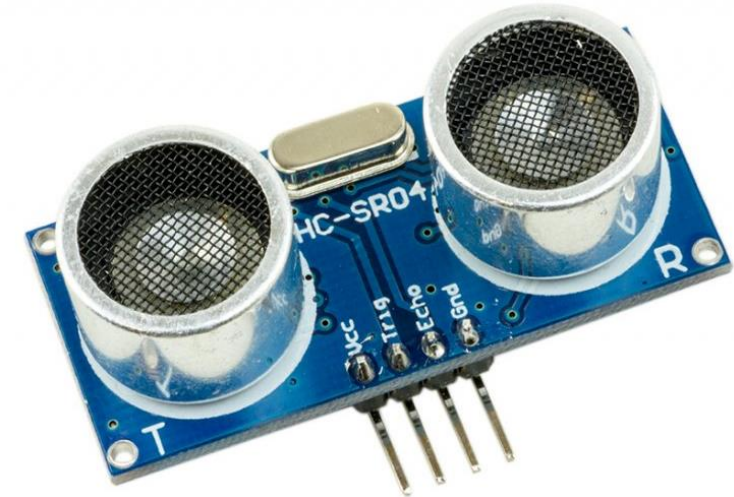

Figure 2. Ultrasonic sensor [8]

Ultrasonic pin configuration

1. VCC: $5 \mathrm{~V}$ DC power supply

2. Trig: trigger signal for starting the transmission with $10 \mu \mathrm{s}$ high time

3. Echo: output

4. GND: ground

Interfacing the Ultrasonic sensor with the Arduino board

$\checkmark$ Ultrasonic sensor, test pin(analog pin) connected to a DC SINE generator(variable voltage source) and voltimeter, the positive pin connected to power, trigger pin connected to pin 3 on the Arduino UNO R3, echo pin connected to the pin 4 on Arduino UNO and GND to ground.

$\checkmark$ Virtual terminal, connected to pin 1 and 0 of the Arduino UNO R3.

$\checkmark$ LED pin connected to pin 13 of Arduino UNO and buzzer to pin8 of the Arduino UNO R3. Input and output terminal were used for these connections.

$\checkmark$ After all connections were made, the Arduino code was loaded on to the Arduino UNO from the archives (hex file).

$\checkmark$ The ultrasonic sensor location was also loaded (hex file).

$\checkmark$ The run/start simulation button was pressed to start simulation of the program.

Rain Sensor Module

Raindrop sensor is basically a board on which nickel is coated in the form of lines. It works on the principal of resistance. Rain Sensor module allows to measure moisture via analog output pins and it provides a digital output when a threshold of moisture exceeds. The module is based on the LM393 op amp. It includes

the electronics module and a printed circuit board that "collects" the rain drops. As rain drops are collected on the circuit board, they create paths of parallel resistance that are measured via the op amp [9]. The sensor is a resistive dipole that shows less resistance when wet and more resistance when dry. When there is no rain drop on board it increases the Resistance so we gets high voltage according to V=IR. When rain drop present it reduces the resistance because water is a conductor of electricity and presence of water connects nickel lines in parallel so reduces resistance and reduces voltage drop across it [9]. 
The LM393 Rain Sensor specification

- Adopts high quality of RF-04 double sided material.

- Area: $5 \mathrm{~cm} \times 4 \mathrm{~cm}$ nickel plate on side,

- Anti-oxidation, anti-conductivity, with long use time;

- Comparator output signal clean waveform is good, driving ability, over $15 \mathrm{~mA}$;

- Potentiometer adjust the sensitivity;

- Working voltage 5V;

- Output format: Digital switching output (0 and 1) and analog voltage output AO;

- With bolt holes for easy installation;

- Small board PCB size: $3.2 \mathrm{~cm} \mathrm{x} 1.4 \mathrm{~cm}$;

- Uses a wide voltage LM393 comparator

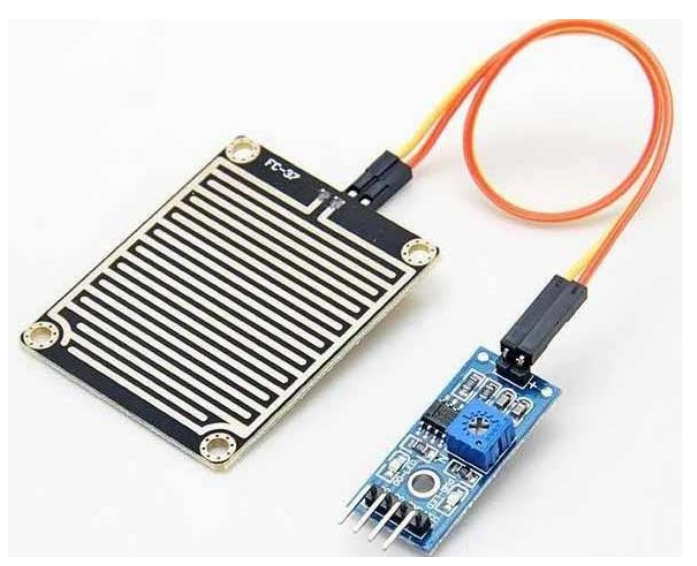

Figure 3. Rain sensor module [8]

\begin{tabular}{|l|l|}
\hline $\begin{array}{l}\text { Rain Sensor } \\
\text { Pin }\end{array}$ & Description \\
\hline Vcc & +5 Volts Power Source \\
\hline GND & $\begin{array}{l}\text { Digital Output. Goes low when moisture } \\
\text { exceeds set threshold. }\end{array}$ \\
\hline D0 & $\begin{array}{l}\text { Analog Output - Zero to five volts. The lower } \\
\text { the voltage, the greater the moisture }\end{array}$ \\
\hline A0 & \begin{tabular}{l} 
Indicates that power is applied \\
\hline POWER LED \\
\hline OUTPUT LED \\
threshold set by sensitivity adjustment.
\end{tabular} \\
\hline $\begin{array}{l}\text { Sensitivity } \\
\text { Adjustment }\end{array}$ & $\begin{array}{l}\text { Clockwise is more sensitive. Counterclockwise } \\
\text { is less sensitive. }\end{array}$ \\
\hline
\end{tabular}

Interfacing the Rain Sensor with the Arduino board

- Connect VCC pin of sensor to $5 \mathrm{~V}$ power supply of Arduino,

- Connect GND pin of sensor to GND of Arduino and

- Connect Analog output pin of sensor to A0 pin of Arduino.

- The rain sensor location was also loaded (hex file).

- The run/start simulation button was pressed to start simulation of the program. I

\section{Gas sensor module}

A smoke sensor is a device that senses smoke, typically as an indicator of fire. Commercial and residential security devices issue a signal to a fire alarm control panel as part of a fire alarm system, while household detectors, known as smoke alarms, generally issue a local audible or visual alarm from the detector itself. The Analog Smoke/LPG/CO Gas Sensor (MQ2) module utilizes an MQ-2 as the sensitive component and has a protection resistor and an adjustable resistor on board. The MQ-2 gas sensor is sensitive to LPG, i-butane, propane, methane, alcohol, Hydrogen and smoke. It could be used in gas leakage detecting equipment in family and industry. The resistance of the sensitive component changes as the concentration of the target gas changes [10]. Pin Configuration for the gas sensor; pin 1 corresponds to VCC, 2 to D0 pin, 3 to A0 pin and 4 to the ground. The smoke sensor is shown in Figure 4 below.

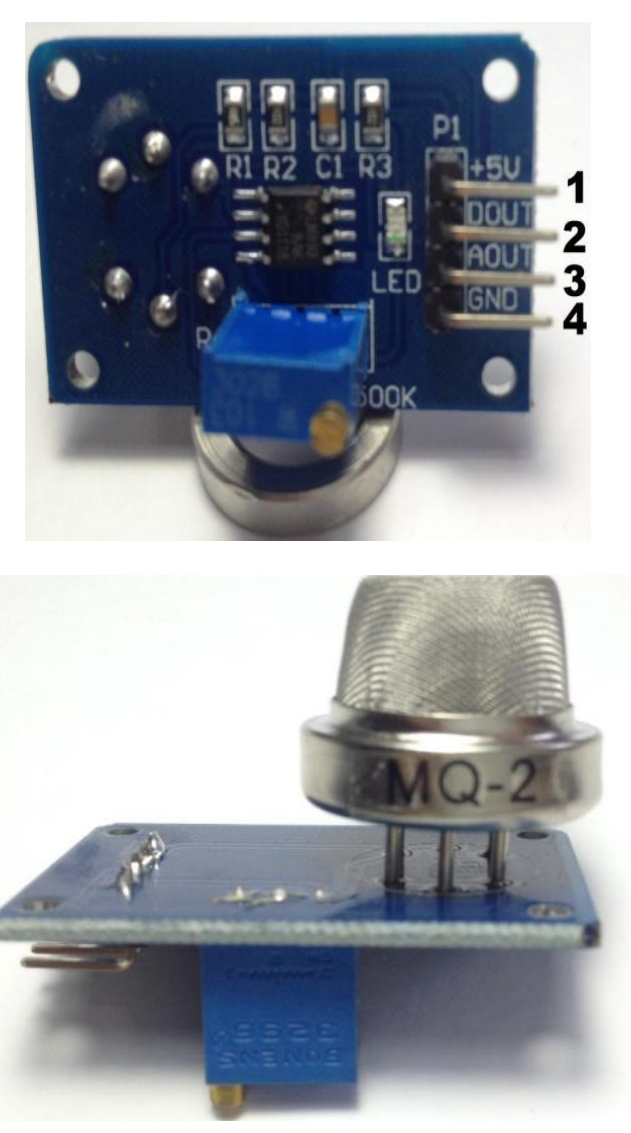

Figure 4. Gas sensor module [10]

Interfacing the smoke sensor with the Arduino board

$\checkmark$ Connect VCC pin of sensor to $5 \mathrm{~V}$ power supply of Arduino,

$\checkmark$ Connect the GND pin of your module to the GND pin of your Arduino.

$\checkmark$ Connect the Output pin of your module to the A1 pin of you Arduino.

$\checkmark \quad$ The smoke sensor location was also loaded (hex file).

$\checkmark$ The run/start simulation button was pressed to start simulation of the program. 


\subsection{RESULTS AND DISCUSSION}

Ultrasonic sensor was used as a proximity switch, in the sense that whenever there is obstacle in the way of ultrasonic sensor (from Figure 5) (in front of the train), it will automatically give an indication through the led which blinks red and the buzzer will continue sounding until the drivers stops the train for the object on the track to be removed. The smoke sensor detects the presence of smoke (from Figure 6) on the train and sends a signal to the driver via an alarm and a led and buzzer installed inside the train, the train operator then takes further steps to eliminate the causes of the smoke on the train. Similarly the rain sensor detects (from Figure 6) the presence of flood on the track up to a certain height, if the water level reaches the height on the track, the rain sensor sends a feedback to the train operator to stop the train. With all this sensor installed on the train, we can reduce railway accident to a significant margin, which will lead to a smooth operation of the railway and increase profitability of the railway company.

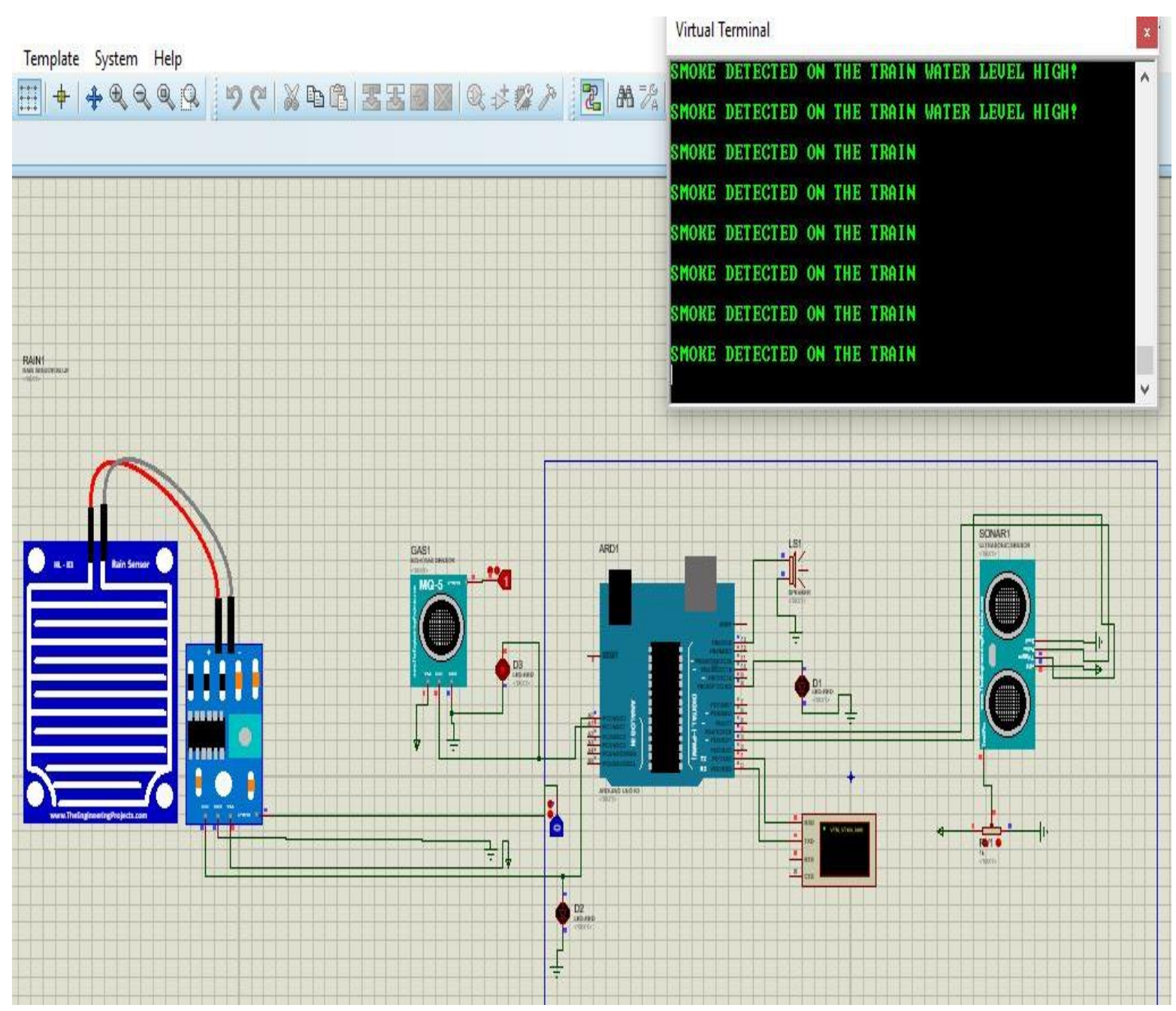

Figure 5. Interfacing Rain, Smoke and Ultrasonic Sensor with the Arduino board 


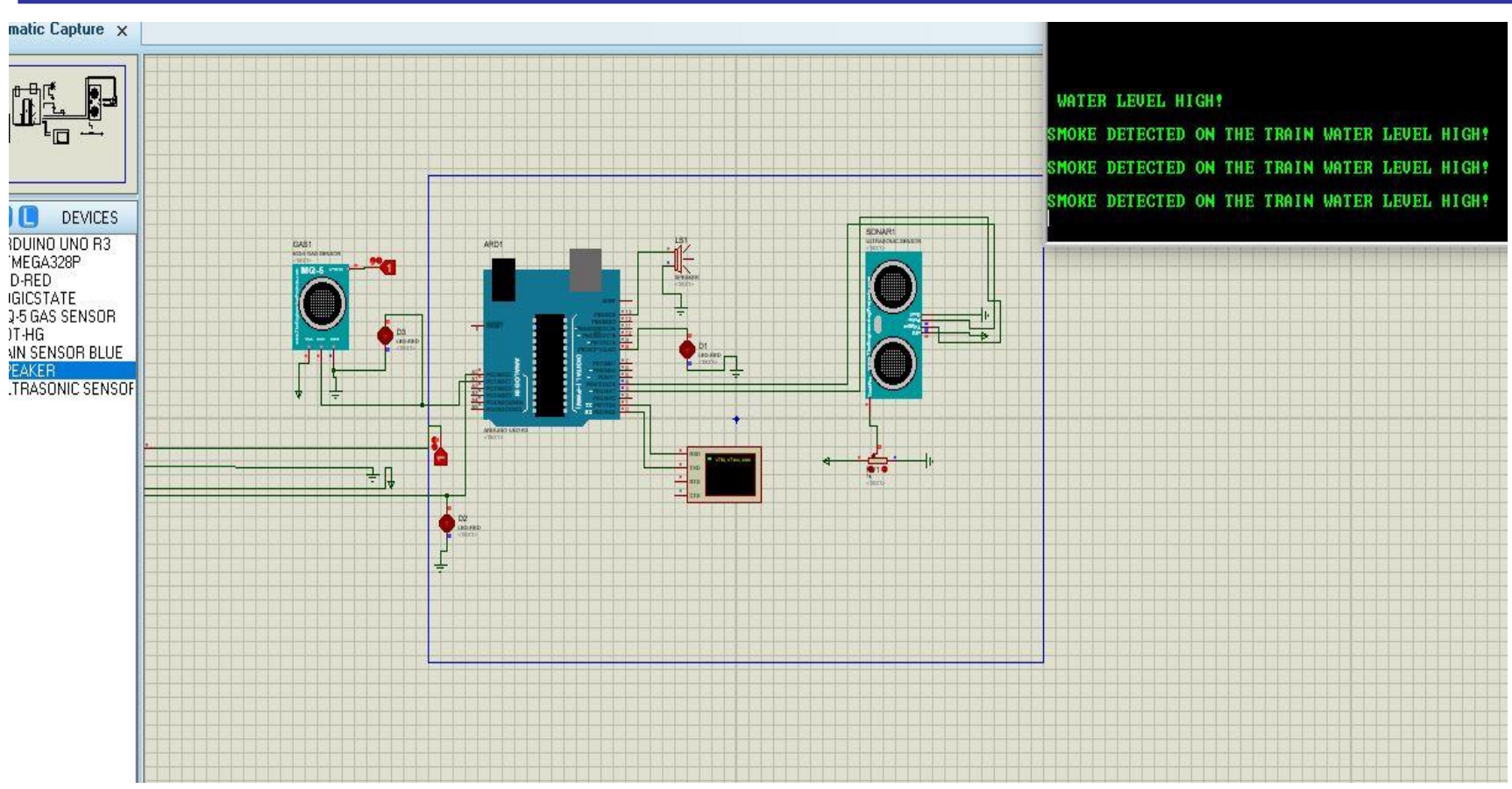

Figure 6. Water and Smoke is detected but no obstacle on track

\section{CONCLUSION}

On this paper, the Proteus simulation using Arduino based safety system is done such that all obstacles in the right of way of the train, smoke in the train and also flooding on the railway track will be detected therefore preventing derailment and collision accidents that cost the railway company a lot of money.

In this paper, a cost effective, low-power embedded system, was designed which facilitate better safety standards for rail tracks for preventing railway accidents due to obstacles on railway tracks, flooding and fire in the train. The result shows that this new innovative technology will increase the reliability of safety systems of railway. By implementing these features in real time application, we can avoid accidents up to a very significant margin.

\section{REFERENCES}

[1] Code of practice for train lighting maintenance on prevention of fires on $110 \mathrm{v}$ dc sg coaches no. El/tl/56-1992 issued by Rdso/Pe/O/0008 - 2005.

[2] Crack detection system for railway track using Ultrasonic and PIR sensor, Prof. P.Navaraja, Volume 05, 2014

[3] Dhiraj Sinha, Farhan Feroz. "Obstacle Detection on Railway Tracks Using Vibration Sensors and Signal Filtering Using Bayesian Analysis," IEEE Sensors Journal Vol. 16, Issue. 3, Feb.1, 2016.

[4] Krishna, ShashiYadav and Nidhi, "Automatic Railway Gate Control Using Microcontroller", Oriental Journal Of Computer Science \&Technology, Vol.6, No.4, December 2013.

[5] J. Xuer, "Visual Monitoring Based Railway Grade Crossing Surveillance System, "Congress on Iamge and Signal Processing, 2008.

[6] https://www.pololu.com/product/2191

[7] http://www.cmra.rec.ri.cmu.edu/content/electro nics/boe/ultrasonic_sensor/1.html

[8] https://www.piborg.org/sensors-1136/hc-sr04

[9] https://electrosome.com/interfacing-rain-sensor-arduino/

[10] https://www.sainsmart.com/products/mq-5 smoke-gas-detectorsensor 